\title{
Numerical Simulation for Residual Stress Distributions of Thermal Barrier Coatings by High Temperature Creep in Thermally Grown Oxide
}

\author{
Jung-Chel Jang ${ }^{\dagger}$ and Sung-Churl Choi \\ Department of Material Science and Engineering, Hanyang University, Seoul 133-791, Korea \\ (Received June 19, 2006; Accepted July 30, 2006)
}

\section{Thermally Grown Oxide의 고온 크리프에 따른 열차폐 코팅의 잔류응력 분포에 관한 유한요소해석}

\author{
장중철 ${ }^{\dagger}$ 최성철 \\ 한양대학교 신소재공학과
}

(2006년 6월 19일 접수; 2006년 7월 30일 승인)

\begin{abstract}
The residual stress changes on thermo-mechanical loading in the interface region of the Thermal Barrier Coating (TBC)/Thermally Grown Oxide (TGO)/Bond Coat (BC) were calculated on the TBC-coated superalloys using a Finite Element Method (FEM). It was found that the residual stress of the interface boundary was dependent upon mainly the oxide formation and the swelling rate of the oxide by creep relaxation. During an oxide swelling, the relaxation of residual stress which is due to creep deformation increased the TBC's life. In the case of the fine grain size of TGO scale, the TBC stresses piled up by oxide swelling could be relaxed by diffusional creep effect of TGO.
\end{abstract}

Key words: Thermal barrier coatings, TGO, Numerical simulation, Creep

\section{1. 서 론}

최신 가스터빈의 고온부 부품은 높은 열응력과 온도의 열악한 조건에서 운전된다. 높은 운전 온도와 잦은 기동. 정지에 의한 열응력은 재료와 코팅의 열화에 큰 역할을 하여 부품의 수명에 악영향을 준다. 가스터빈의 내열합금 고온부 부폼들은 그들의 융점에 이미 근접하여 운전되고 있으므로 열차폐 코팅이 제공하는 단열 성능에 의존하고 있다. ${ }^{1,2)}$

$\mathrm{ZrO}_{2}-7 \% \mathrm{Y}_{2} \mathrm{O}_{3}$ 코팅은 우수한 내열성을 갖고 있으며 ${ }^{3)}$ 금 속의 온도를 최대 $170^{\circ} \mathrm{C}$ 까지 감소시킨다. ${ }^{4)}$ 그러나 열차 폐 코팅은 $\mathrm{ZrO}_{2}-7 \% \mathrm{Y}_{2} \mathrm{O}_{3}$ 의 Top Coat(TC), 금속 모재와 top coat 사이에 증착되어 모재의 산화와 고온 부식을 방 지해 주며 사용중에 세라믹과 모재사이의 결속력을 유지 시키는 $\operatorname{MCrAIY}(\mathrm{M}=\mathrm{Ni}, \mathrm{Co}$ 또는 $\mathrm{NiCo})$ 의 Bond $\operatorname{Coat}(\mathrm{BC})$ 및 $\mathrm{BC}$ 의 산화에 의해 $\mathrm{BC}$ 와 $\mathrm{TC}$ 사이에 위치한 $\mathrm{TGO}$ (Thermally Grown Oxide)로 구성되어 있어 전체적으로 두 께가 두껍고 서로 다른 특성의 코팅층을 조합함으로써 발 생하는 잔류응력에 의해 이전까지는 주로 운전 중 응력

\footnotetext{
${ }^{\dagger}$ Corresponding author: Jung-Chel Jang

E-mail : chel@kepco.co.kr

Tel : +82-42-865-5415 Fax : +82-42-865-5444
}

이 작게 작용하는 고정읙 부품에 적용되었지만, 최근의 가스터빈에서는 매우 운전 조건이 열약한 1단 회전익에 도 적용되어 지고 있다., ${ }^{5,6)}$

열차폐 코팅이 보다 광범위하며 가스터빈의 신뢰성에 가장 중요한 1 단 회전익에 적용됨에 따라 운전조건에서 열차폐 코팅의 거동을 예측하고 손상 모델을 구축하는 필 요성이 제기되고 있다. 열차폐 코팅이 가열-냉각 사이클을 겪으면 표면에서 transient heat flux가 작용하면서 $\mathrm{TBC}$ 표 면에서 균열이 시작되어 코팅 전 두께에 걸쳐 관통된다. 이전의 연구 ${ }^{7-9)}$ 에 의하면 소결, 치밀화 및 응력 완화/크리 프의 형태로써 열적으로 활성화된 시간 의존성(viscoplastic) 변형에 의해 가열-냉각 사이클의 종료시점에서 인장응력 을 발생시킨다. 이러한 인장응력은 포면 균열의 시작과 성장에 중요한 인자이다.

열차폐 코팅이 $1000^{\circ} \mathrm{C}$ 이상으로 가열되면 세라믹 코팅 은 모재에서 박리되는데, 이러한 ceramic buckling은 각 코 팅 요소들의 소성유동(plastic flow) 거동에 대한 이해를 필요로 하고 있으며, 이러한 현상은 열차폐 코팅의 주요 손상인자중의 하나로 여겨지고 있다. ${ }^{10-12)}$ 열차폐 코팅의 박리의 원인을 이해함으로써 고온에서의 거동을 예측할 수 있으며 발생할 수 있는 문제점들을 예방할 수도 있을 것이다. 본 연구에서는 열차폐 코팅 처리된 초내열합금 (TBC-coated superalloy)에 대해 일반적으로 적용되고 있 


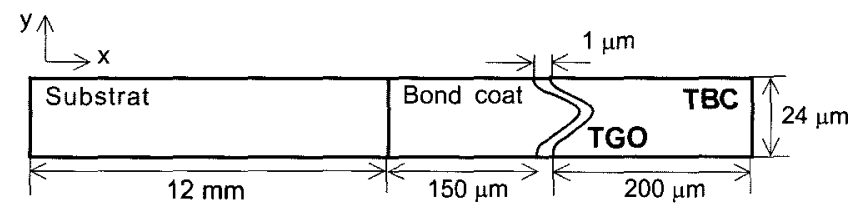

(a)

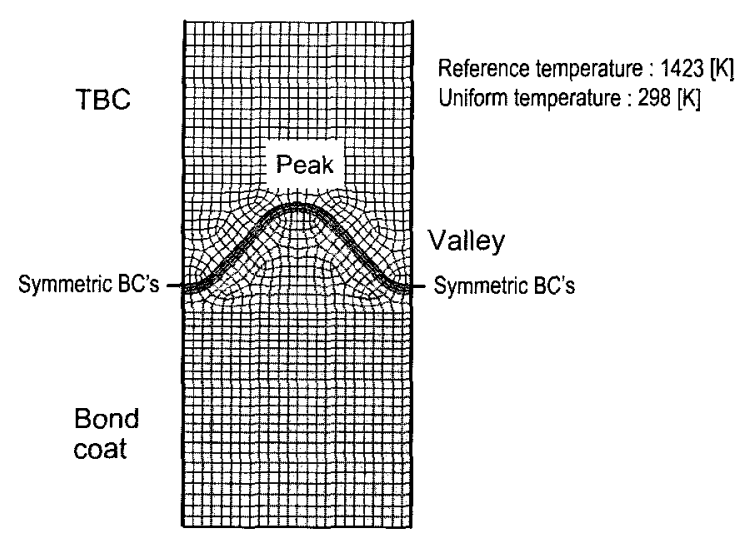

(b)

Fig. 1. Geometry and finite element model for analysis: (a) shows a cross-section of the axially symmetric model and (b) shows a detail of the finite element model in the region of the bond coat/TBC interface.

는 대기화염용사(APS, Air Plasma Spray) 공정으로 열차 폐 코팅을 모델링하여 열적·기계적 부하에서 $\mathrm{TGO}$ 의 일 차 소성(linear plastic) 및 점탄소성(elastic viscoplastic) 거 동에 의한 각 계면에서의 잔류응력 분포 변화를 고찰하였다.

\section{2. 실험 방법}

모델의 형상은 반구형의 solid cylinder로써 축방향으로 무한히 확장된다고 가정한다. 본 모델은 길이가 $12 \mathrm{~mm}$ 인 합금 모재와 평균 두께가 $150 \mu \mathrm{m}$ 인 bond coat 및 $200 \mu \mathrm{m}$ 인 $\mathrm{TBC}$ 층으로 구성되어 있다. Bond coat와 $\mathrm{TBC}$ 사이의 계면 영역은 높이가 $1 \mu \mathrm{m}$ 이고 길이가 $24 \mu \mathrm{m}$ 인 주기적으 로 변화하는 사인파 형상으로 모델을 제작하였다. 본 모 델의 구체적인 형상을 Fig. 1에 나타내었으며, 모델의 상 세한 설명은 이전의 연구보고 ${ }^{13)}$ 에 설명되어 있다.

본 해석에 사용된 각 $\mathrm{TBC}$ 성분의 거동을 지배하는 재 료의 열탄성(thermoelastic) 및 점소성(viscoplastic) 파라미 터를 Tables 1 4에 나타내었다. 지르코니아 top coat, bond coat 및 $\mathrm{Ni}$ 기 초내열합금 모재의 점소성 거동은 다음과 같은 다축 하중 조건으로 일반화한 power-law 크리프 방 정식으로 모델화하였다.

$$
\dot{\varepsilon}_{\mathrm{ij}}^{\mathrm{c}}=\frac{3 \mathrm{~F}\left(\sigma_{\mathrm{e}}, \mathrm{T}\right)}{2 \sigma_{\mathrm{e}}} \sigma_{\mathrm{ij}}^{\prime}
$$

여기서, $\sigma_{\mathrm{ij}}^{\prime}$ 는 응력 편차, $\sigma_{\mathrm{e}}=\sqrt{3 / 2 \sigma_{\mathrm{ij}}^{\prime} \sigma_{\mathrm{ij}}^{\prime}}$ 의 성분이며, 그
Table 1. Thermoelastic Material Properties and Creep Parameters of the Zirconia Top Coat

\begin{tabular}{cccccc}
\hline Temperature & $\begin{array}{c}\mathrm{E} \\
(\mathrm{GPa})\end{array}$ & $v$ & $\begin{array}{c}\alpha \\
\left(10^{-6} \rho \mathrm{C}\right)\end{array}$ & $\begin{array}{c}\mathrm{A} \\
\left(\mathrm{MPa}^{-\mathrm{n}} / \mathrm{s}\right)\end{array}$ & $\mathrm{n}$ \\
\hline $1200^{\circ} \mathrm{C}$ & 25.4 & 0.33 & 12.5 & $1.85 \times 10^{-7}$ & 3.0 \\
$1100^{\circ} \mathrm{C}$ & 25.4 & 0.33 & 12.1 & $7.40 \times 10^{-8}$ & 3.0 \\
$1000^{\circ} \mathrm{C}$ & 25.4 & 0.33 & 11.8 & $2.57 \times 10^{-8}$ & 3.0 \\
$900^{\circ} \mathrm{C}$ & 25.4 & 0.33 & 11.4 & $7.42 \times 10^{-9}$ & 2.0 \\
$800^{\circ} \mathrm{C}$ & 25.4 & 0.33 & 11.0 & $1.70 \times 10^{-9}$ & 2.0 \\
$700^{\circ} \mathrm{C}$ & 25.4 & 0.33 & 10.6 & $2.89 \times 10^{-10}$ & 1.0 \\
$500^{\circ} \mathrm{C}$ & 25.4 & 0.33 & 9.8 & $2.10 \times 10^{-12}$ & 1.0 \\
$10^{\circ} \mathrm{C}$ & 25.4 & 0.33 & 7.6 & $2.01 \times 10^{-30}$ & 1.0 \\
\hline
\end{tabular}

Table 2. Thermoelastic Material Properties and Creep Parameters of the NiCrAlY Bond Coat

\begin{tabular}{cccccc}
\hline Temperature & $\begin{array}{c}\mathrm{E} \\
(\mathrm{GPa})\end{array}$ & $\mathcal{v}$ & $\begin{array}{c}\alpha \\
\left(10^{-6} \mathrm{\rho} \mathrm{C}\right)\end{array}$ & $\begin{array}{c}\mathrm{A} \\
\left(\mathrm{MPa}^{-n} / \mathrm{s}\right)\end{array}$ & $\mathrm{n}$ \\
\hline $1200^{\circ} \mathrm{C}$ & 156.0 & 0.27 & 14.4 & $7.40 \times 10^{-6}$ & 3.0 \\
$1100^{\circ} \mathrm{C}$ & 156.0 & 0.27 & 14.2 & $1.17 \times 10^{-6}$ & 3.0 \\
$1000^{\circ} \mathrm{C}$ & 156.0 & 0.27 & 14.0 & $1.37 \times 10^{-7}$ & 3.0 \\
$900^{\circ} \mathrm{C}$ & 156.0 & 0.27 & 13.8 & $1.14 \times 10^{-8}$ & 2.0 \\
$800^{\circ} \mathrm{C}$ & 156.0 & 0.27 & 13.6 & $5.90 \times 10^{-10}$ & 2.0 \\
$700^{\circ} \mathrm{C}$ & 156.0 & 0.27 & 13.4 & $1.66 \times 10^{-11}$ & 1.0 \\
$500^{\circ} \mathrm{C}$ & 156.0 & 0.27 & 13.0 & $8.20 \times 10^{-16}$ & 1.0 \\
$10^{\circ} \mathrm{C}$ & 156.0 & 0.27 & 12.0 & $4.39 \times 10^{-40}$ & 1.0 \\
\hline
\end{tabular}

Table 3. Thermoelastic Material Properties and Creep Parameters of the Ni Substrate

\begin{tabular}{cccccc}
\hline Temperature & $\begin{array}{c}\mathrm{E} \\
(\mathrm{GPa})\end{array}$ & $v$ & $\begin{array}{c}\alpha \\
\left(10^{-6} \mathrm{C} \mathrm{C}\right)\end{array}$ & $\begin{array}{c}\mathrm{A} \\
\left(\mathrm{MPa}^{-\mathrm{n}} / \mathrm{s}\right)\end{array}$ & $\mathrm{n}$ \\
\hline $1200^{\circ} \mathrm{C}$ & 156.0 & 0.27 & 19.3 & $2.25 \times 10^{-9}$ & 3.0 \\
$1100^{\circ} \mathrm{C}$ & 156.0 & 0.27 & 18.8 & $4.36 \times 10^{-10}$ & 3.0 \\
$1000^{\circ} \mathrm{C}$ & 156.0 & 0.27 & 17.8 & $3.08 \times 10^{-10}$ & 3.0 \\
$900^{\circ} \mathrm{C}$ & 156.0 & 0.27 & 16.9 & $1.79 \times 10^{-10}$ & 2.0 \\
$800^{\circ} \mathrm{C}$ & 156.0 & 0.27 & 15.9 & $5.13 \times 10^{-11}$ & 2.0 \\
$700^{\circ} \mathrm{C}$ & 156.0 & 0.27 & 15.2 & $2.28 \times 10^{-29}$ & 1.0 \\
$500^{\circ} \mathrm{C}$ & 156.0 & 0.27 & 14.4 & $1.00 \times 10^{-34}$ & 1.0 \\
$10^{\circ} \mathrm{C}$ & 156.0 & 0.27 & 12.0 & $4.85 \times 10^{-36}$ & 1.0 \\
\hline
\end{tabular}

Table 4. Thermoelastic Material Property of the $\mathrm{Al}_{2} \mathrm{O}_{3}$

\begin{tabular}{cccccc}
\hline Temperature & $\begin{array}{c}\mathrm{E} \\
(\mathrm{GPa})\end{array}$ & $\cup$ & $\begin{array}{c}\alpha \\
\left(10^{-6} / \mathrm{C}\right)\end{array}$ & $\begin{array}{c}\mathrm{A} \\
\left(\mathrm{MPa}^{-\mathrm{n}} / \mathrm{s}\right)\end{array}$ & $\mathrm{n}$ \\
\hline $1200^{\circ} \mathrm{C} \rightarrow 0^{\circ} \mathrm{C}$ & 380 & 0.26 & 8.6 & - & - \\
\hline
\end{tabular}

리고

$$
\mathrm{F}\left(\sigma_{e}, \mathrm{~T}\right)=\mathrm{A}(\mathrm{T}) \sigma_{\mathrm{e}}^{\mathrm{n}(\mathrm{T})}
$$

여기서, 온도 의존 파라미터인 $\mathrm{A}, \mathrm{n}$ 는 $10^{\circ} \mathrm{C} \sim 1200^{\circ} \mathrm{C}$ 범위 


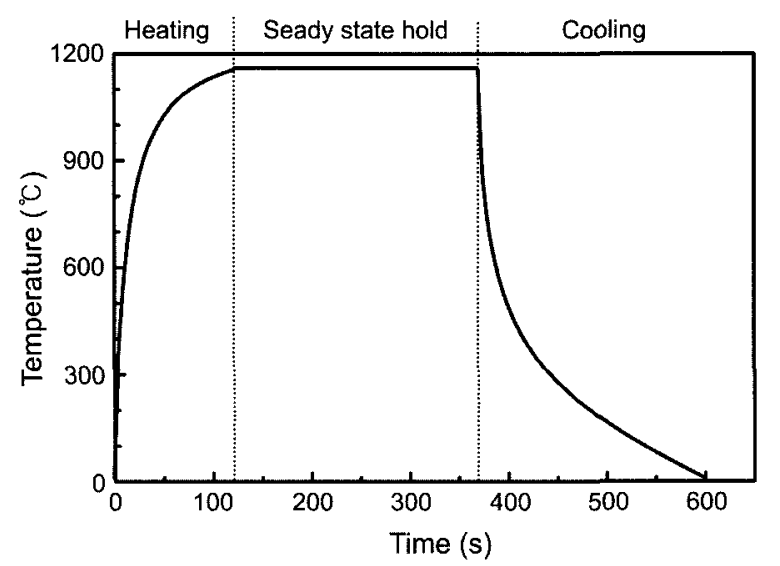

Fig. 2. Standard thermal profile used in the finite element model.

에 대하여 표에 나타낸 바와 같다. 전체 모델에서 bond coat와 $\mathrm{TBC}$ top coat는 표에 나타낸 바와 같이 재료에 주 어진 특성에 따라 점탄소성 거동을 가정하였지만, $\mathrm{TGO}$ 는 각각 일차 소성과 점탄소성 거동을 구분하여 해석되 었다. 일반적으로 용사된 지르코니아 top coat 층이 완전 소결된 지르코니아보다 크게 비탄성(inelastic) 거동을 보 이는 것을 본 모델에서는 고려하지 않았지만 이러한 현상 은 용사과정에서 발생한 기공과 미세균열에 의해 활성화 된 국부적인 변형 메커니즘에 기인한다고 보고되었다. ${ }^{14)}$ 또한 본 논문에서는 $\mathrm{TGO}$ 를 순수한 $\alpha-\mathrm{Al}_{2} \mathrm{O}_{3}$ 로 가정하였다.

본 모델에 적용된 열 사이클은 Fig. 2에 나타낸 바와 같 이 이전의 연구 ${ }^{15)}$ 에서 사용된 사이클과 동일하게 $20^{\circ} \mathrm{C}$ 에 서 $1150^{\circ} \mathrm{C}$ 까지 $120 \mathrm{~s}$ 동안 가열하고 $240 \mathrm{~s}$ 동안 유지하며 $240 \mathrm{~s}$ 의 냉각시간을 갖도록 구성되었다. 그리고 이러한 실 험적인 시간설정은 현실적으로는 너무 짧은 가상적인 설
정으로 실재 사용시간을 고려하기 위해 유지시간을 $2400 \mathrm{~s}$ 까지 증가시킨 열 사이클에 대한 모사실험도 수행하였다. 모델은 열전도를 고려하지 않도록 등온상태로 가열된다 고 가정하였다.

\section{3. 결과 및 고찰}

\subsection{TGO가 형성되지 않은 상태에서의 열적 사이클 모사}

$\mathrm{TGO}$ 형성에 따른 영향을 비교하기 위하여 가장 이상 적인 $\mathrm{TGO}$ 가 형성되지 않은 상태에서 열 사이클 동안 응 력분포의 형상을 고찰하였다. Fig. 3 에는 1 차 사이클에 대 한 radial stress의 분포를 보여 준다. Bond coat와 TBC 사이의 열팽창 계수차로 인하여 가열되는 동안 "peak"에 서 압축응력이 발생하며 “valley"에서는 이와 반대로 절 대값의 크기가 비슷한 인장응력이 발생되어 서로 대응하 는 것을 알 수 있다(Fig. 3(a)). Radial stress는 주로 국부 적인 형상에 의해 지배되지만 2 차원적인 평면상의 응력 은 superalloy substrate에 대한 열팽창 계수의 불일치로 기 술할 수 있다. 이러한 정의로 응력분포를 표현한다면 $\mathrm{TBC}$ 에서의 모든 응력성분은 인장응력이며 bond coat에서는 압축응력이 된다. Fig. $3(\mathrm{~b})$ 에서 보는 바와 같이 $1150^{\circ} \mathrm{C}$ 에 서 유지되는 동안 bond coat와 TBC에서 발생하는 급격한 크리프로 인하여 모든 응력들이 거의 0 에 근접하게 완화 된다. 이러한 결과들을 "peak", "off-peak" 및 "valley"의 위치에 따른 radial stress를 시간의 함수로 나타낸 Fig. 4 에서 설명될 수 있다. 초기의 $120 \mathrm{~s}$ 동안 가열시 peak부에 서 - $100 \mathrm{MPa}$ 에 도달한 응력이 냉각시에 이러한 응력상태 가 반전되며 $200 \mathrm{MPa}$ 까지 상승하며, valley에서의 웅력은 초기의 $+50 \mathrm{MPa}$ 에서 $-220 \mathrm{MPa}$ 에 감소한다. 이러한 냉각 시 peak부에서 발생되는 인장응력 수치는 용사 코팅된

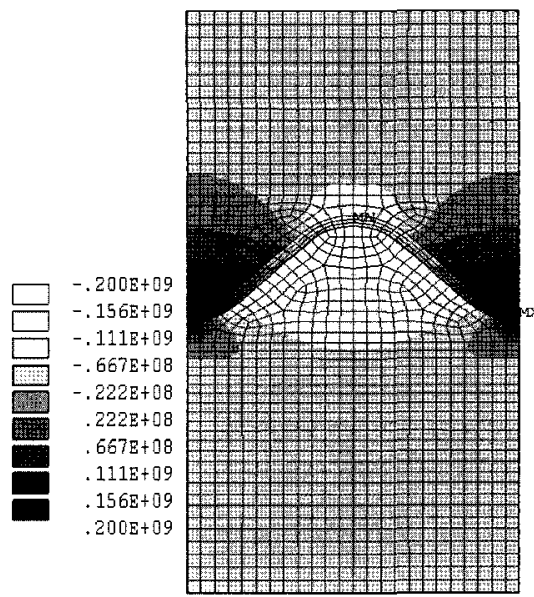

(a)

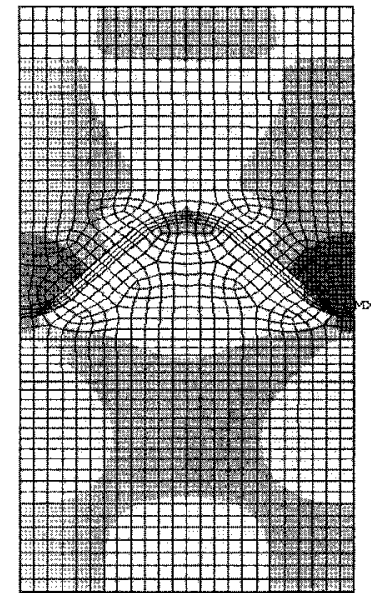

(b)

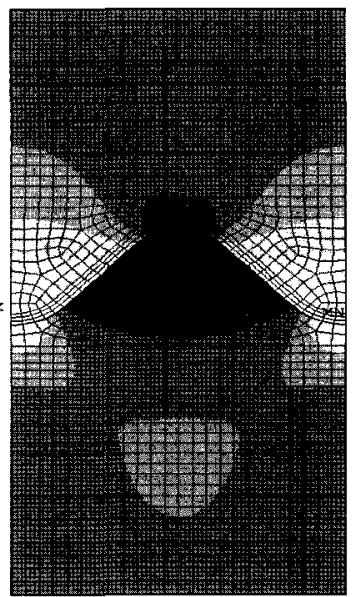

(c)

Fig. 3. Evolution of the radial stress during cycle No. 1 after (a) $20 \mathrm{~s}$, (b) $360 \mathrm{~s}$ (end of hold time, $1150^{\circ} \mathrm{C}$ ), and (c) $600 \mathrm{~s}$ (end of $1 \mathrm{st}$ cycle, $20^{\circ} \mathrm{C}$ ). No TGO formation occurs in this simulation. 


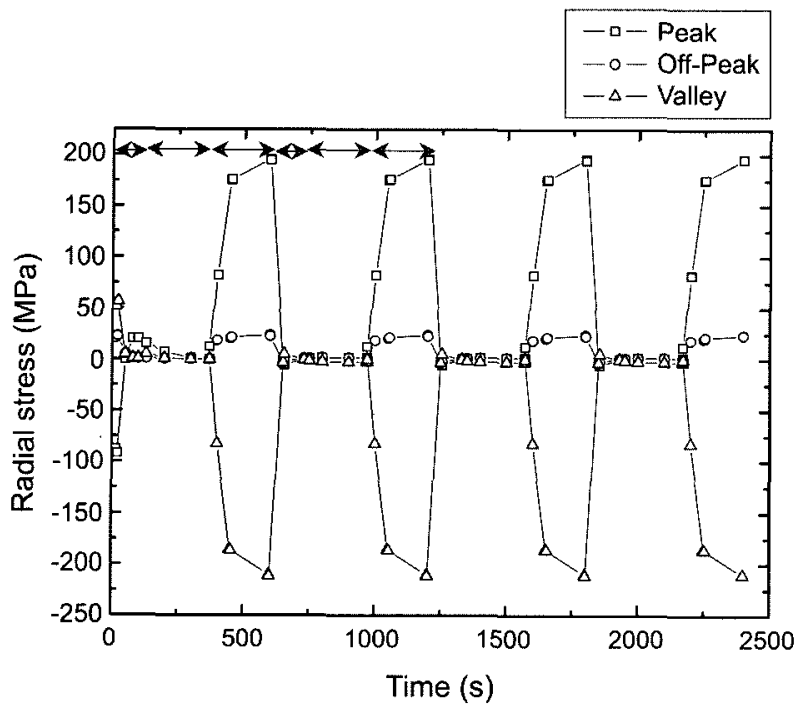

Fig. 4. Time dependence of the radial TBC stress at peak, offpeak and valley. No TGO formation occurs in this simulation.

$\mathrm{TBC}$ 의 파단 강도를 초과하는 것이므로 peak부 부근에서 국부적인 손상 가능성이 있다. ${ }^{15)}$ 이러한 결과로 본다면 코팅은 1 차 사이클의 가열시에도 valley부에서 손상이 발 생할 수 있다고 보아야 하지만, 크리프 변형의 시작으로 인하여 인장응력이 상당히 감소되어 손상에 영향을 미치 지 못한다. Fig. 4에는 위에서 설명한 바와 같이 초기 사 이클 완료 후 응력이 재분포되며 그 후로는 일정한 형태 로 유지되는 것을 볼 수 있다. 이것은 최초 가열시 고온 에서 유지시간동안 응력이 완전히 완화되었기 때문인 것 으로 판단된다.

\section{2. 일차 탄성 거동의 TGO에 대한 열적 사이클 모사}

다음으로는 다공성으로 외부의 가스가 top coat를 관통 하여 bond coat가 산화되어 $\mathrm{TBC}$ top coat와 bond coat 사이에 TGO가 형성되고 사이클이 진행됨에 따라 swelling 이 발생한다고 가정한 사이클 2, 3 및 4에 대한 조건하에 서 응력 상태를 계산하였다. 최초 사이클 조건(3.1절의 산 화되지 않은 초기상태)을 시작 상태로 설정하였다. TGO 는 입자 크기가 충분히 크다는 $(>>1 \mu \mathrm{m})$ 가정을 반영하 여 일차 소성적으로 거동하는 것으로 가정할 수 있다. ${ }^{11)}$ 이전에 서술한 바와 같이 매 사이클마다 산화물이 $0.33 \mu \mathrm{m}$ 씩 선형적으로 성장한다고 가정하였다. $240 \mathrm{~s}$ 동안에 대하 여 이와 같은 성장 속도는 비현실적으로 너무나 빠른 가 정이므로 본 모델을 사용하여 유지 시간을 2400s로 증가 시켜 모사하였다.

Fig. 5는 4차 사이클에서 유지시간 종료 직후의 잔류응 력 분포의 예를 보여주며, Fig. 6은 각 지점에서 얻어진 크기를 시간에 대하여 도시한 것이다. Fig. 6 에 의하면 1

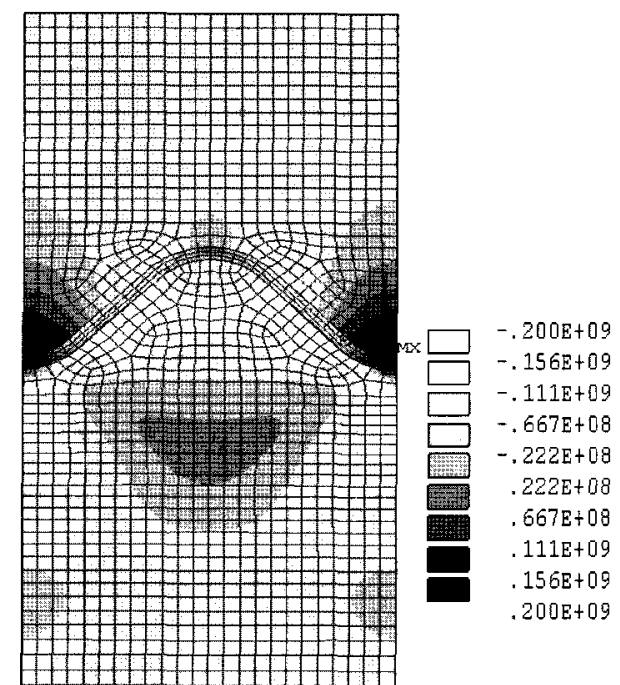

Fig. 5. Evolution of the radial stress during cycle No. 4 at the end of the elevated temperature hold time. The TGO is assumed to behave linear elastic. TGO thickness is $1 \mu \mathrm{m}$.

차 사이클 후 $\mathrm{TGO}$ 의 swelling에 의해 응력 상태가 반전 되며 valley부에는 큰 인장응력을 나타내며, peak부에서는 valley부 크기의 절반 크기의 압축응력을 발생시킨다. 이 러한 거동은 creep relaxation과 swelling이 서로 상반되는 메커니즘을 야기한다는 것에 이해하여야 하며, 전자는 peak부와 valley부의 인장응력과 압축응력의 완화를 초래 하며, 후자는 $\mathrm{TGO}$ 가 확장됨에 따라 응력의 크기를 증가 시키는 메커니즘이다. 결론적으로 swelling rate가 응력 완 화속도보다 상당히 크다면 잔류응력은 유지시간동안 응 력은 당연히 증가하게 되며 냉각된 후에는 고온에서 동 력이 완전하게 완화되는 $\mathrm{TGO}$ 가 없는 가정과는 달리 응력 상태의 부호가 반전되며 그 크기도 열팽창 계수의 차 이에 의해 발생하는 변형으로 인하여 상당히 커진다.

Fig. 6에서 유지시간의 종료시점에서 관찰되는 응력의 감소는 swelling rate의 점진적인 감소에 기인하며, 인장등력과 압축응력이 넝각시에 더욱 증가되는 것은 Young's modulus의 온도 의존성에 의한 것이다. 또한 $1150^{\circ} \mathrm{C}$ 에서 유지시간동안 $\mathrm{TBC}$ 의 응력 수준은 2 차 사이클 이후 사이 클이 증가함에 따라 점진적으로 감소되는데 이것은 새토 운 $\mathrm{TGO}$ 층이 인접한 $\mathrm{TBC}$ 와 bond coat 및 이전에 형성 된 TGO로 확장되지 않으며 2차원적인 평면상의 swelling 은 산화물의 두께가 증가할수록 더욱 구속되는 반면에 측 면상의 swelling은 산화물의 두께에 영향을 받지 않는다는 가정 때문이다. Fig. 6의 결과에서 swelling에 대한 가정의 단순화함에 따라 cycle No. 2는 순수한 등방성 swelling과 유사하며 cycle No. 4는 산화물의 성장이 측면에서 우선 하는 조건에 대한 전형적인 응력상태이다.

산화물의 일차 탄성 거동에 의한 swelling은 고온에서 


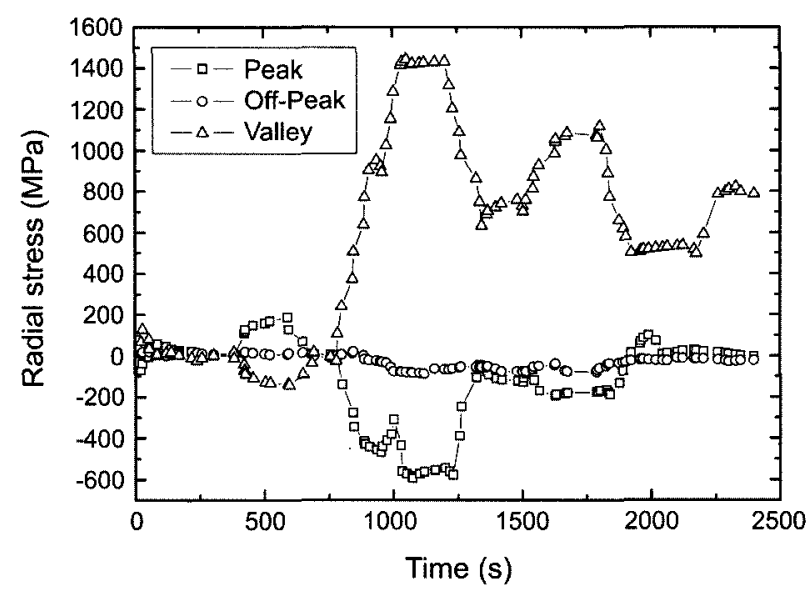

Fig. 6. Time dependence of the radial TBC stress at peak, offpeak and valley. Linear elastic behavior of the TGO and oxide growth rate of $0.33 \mu \mathrm{m}$ per cycle assumed.

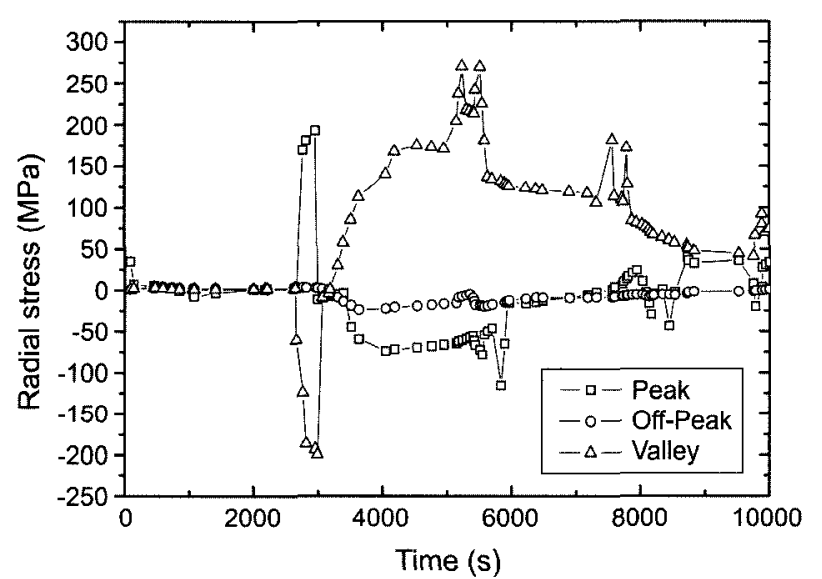

Fig. 7. Time dependence of the radial TBC stress at peak, offpeak and valley. The holding time increased from 240 to 2400s. Linear elastic behavior of the TGO and oxide growth rate of $0.33 \mu \mathrm{m}$ per cycle assumed.

열팽창 계수 불일치에 의한 응력을 증가시켜 $\mathrm{TBC}$ 의 valley 에서 인장 잔류응력을 증가시킨다. 이러한 영향의 크기는 산화물 성장의 등방성 및 swelling과 creep relaxation 속도 사이의 비율에 크게 의존한다. 이러한 현상은 유지시간이 보다 현실적으로 연장시켜 해석한 Fig. 7에서 잘 이해될 수 있다. $1150^{\circ} \mathrm{C}$ 에서 유지시간동안의 응력 크기가 이전의 사이클에서 보다 감소된 것은 creep relaxation을 위한 시 간이 증가하기 때문이다. Fig. 6과 응력의 변화 거동은 유 사하지만, 다른 점은 사이클에서 냉각과 재가열 시간동안 peak부와 valley부에서 이중 피크가 관찰된 것이다. 이러 한 거동은 냉각시에는 elastic modulus의 증가에 의해 응 력 크기가 상대적으로 증가하며, 약 $900^{\circ} \mathrm{C}$ 까지의 고온에 서는 bond coat에서 응력을 빠르게 완화시키므로 열팽창 계수 차에 의한 효과가 중요한 역할을 하지 않는다. 최고
온도까지 도달하면 응력 완화에 의하여 이전의 유지시간 에서 발생한 응력보다 낮은 응력수준을 나타낸다. 보다 낮은 온도에서 이 두 효과는 서로 상호작용하여 냉각시 에는 응력을 감소시키며, 가열시에는 응력을 상승시킨다. Zhou 등 ${ }^{16)}$ 은 전형적인 $\mathrm{TBC}$ 계에 대하여 elastic 상태에 대 한 응력분포를 모사하였다. 계면에서의 잔류응력은 가열 의 초기 단계에서 $\mathrm{TGO}$ 에 무관하게 인장력이 작용하지 만, 그 기간은 8s에 불과하였다고 하였으며, 가열과 유지 기간에는 계면에서 압축응력이 작용하며 이러한 응력은 열팽창 계수의 차이에 기인한다고 하였다. 따라서 $\mathrm{TGO}$ 를 고려하지 않는다면 $\mathrm{TGO}$ 를 고려한 경우보다 인장응력 의 크기가 보다 작아지게 된다. 이러한 사실을 바탕으로 각 계면에서의 인장응력의 크기를 예측한다면 재료 특성 표에 나타낸 바와 같이 $\mathrm{TGO} / \mathrm{bond}$ coat 계면보다 열팽창 계수 차이가 큰 $\mathrm{TBC} / \mathrm{TGO}$ 계면에서 더욱 커지리라는 것 을 알 수 있다.

\section{3. 점탄소성 거동의 TGO에 대한 열적 사이클 모사}

고온에서 $\mathrm{TGO}$ 의 거동은 입자크기가 충분히 크다면 본 질적으로 이전에서 관찰한 바와 같이 탄성적이라고 가정 한다. 그러나 입자 크기가 본 모델에서 설정한 (element의 높이가 $0.33 \mu \mathrm{m}$ ) 바와 같이 $\ll<1 \mu \mathrm{m}$ 이라면 점탄성 거동을 고려해야 한다. 이전과 같이 초기 사이클은 산화 현상을 배제한 상태(without $\mathrm{TGO}$ )에서 시작하였으며 사이클이 증 가할 때마다 $0.33 \mu \mathrm{m}$ 씩 선형적으로 $\mathrm{TGO}$ 의 두께를 증가 시켰다.

Figs. 8과 9는 $\mathrm{TBC}$ 의 점탄성 거동을 고려한 응력 분포 결과를 보여준다. Fig. 9에 의하면 고온에서 유지되는 동 안 모든 응력이 0 으로 나타났는데 이는 이전에 언급한 바

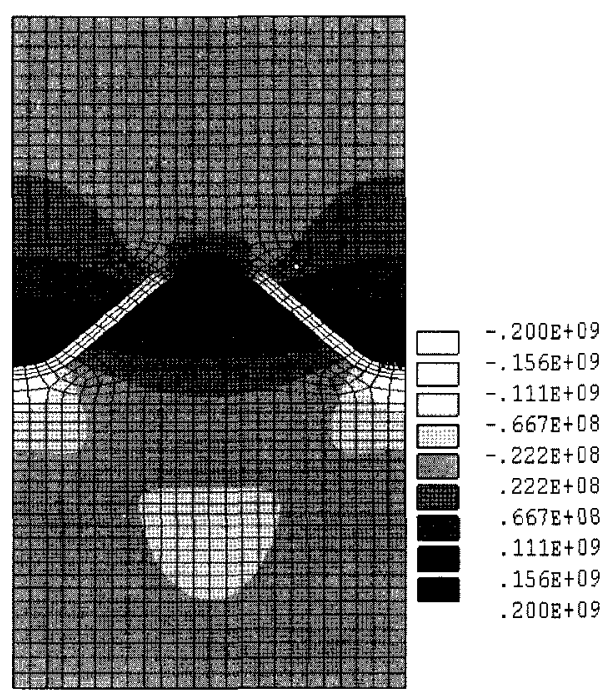

Fig. 8. Radial stress during cycle No. 4 after cooling to $20^{\circ} \mathrm{C}$. The TGO is assumed to behave elastic-viscoplastic. TGO thickness is $1 \mu \mathrm{m}$. 


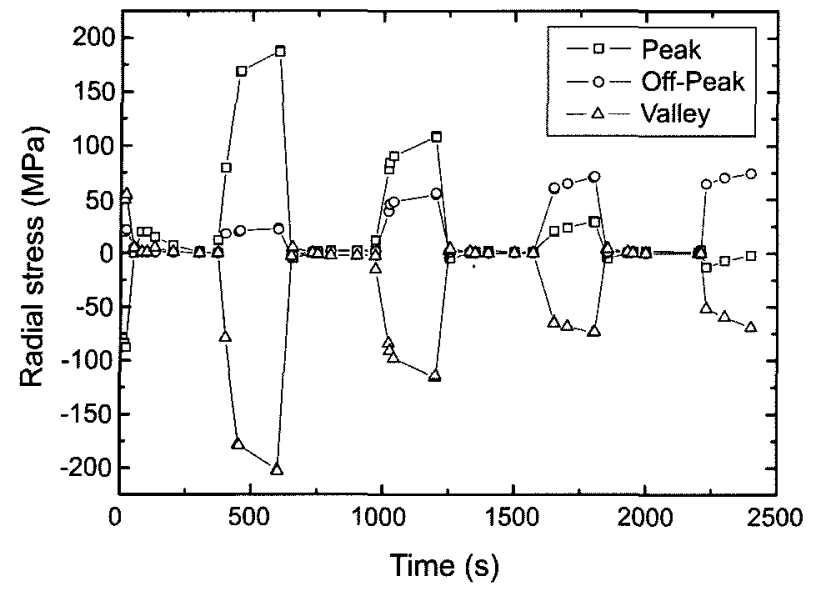

Fig. 9. Time dependence of the radial TBC stress at peak, offpeak and valley. Elastic-viscoplastic behavior of the TGO and oxide growth rate of $0.33 \mu \mathrm{m}$ per cycle assumed.

와 같이 TGO swelling에 의해 상당한 응력이 코팅에 생 성된다는 3.2절에서 서술한 사실과 상충된 결과이다. 이 것은 swelling에 의한 변위는 $\mathrm{TBC}$ 에 미치는 부하가 무시 가능하므로 $\mathrm{TGO}$ 의 물질 유동에 의해 완화된다는 것을 보여준다. TGO의 크리프가 없는 Fig. 5의 응력 분포상태 에서 관찰해보면 물질의 이동은 주로 peak부 부근(압축응 력)에서 valley부(인장응력)로 이송된다. 그러나 swelling에 의한 부피 변화는 $\mathrm{TGO}$ 의 크리프에 의해서만 수용할 수 없으므로 bond coat와 $\mathrm{TBC}$ 의 크리프도 어느 정도의 제한 된 범위내에서 고려해야 한다.

Fig. 9의 사이클에 대한 응력 변화에 의하면 고온 유지 시간의 종료 후 발생하는 응력의 상태는 Fig. 4 와 유사하 다. 그러나 응력의 크기는 산화물이 없을 경우 1 차 사이 클 종료 후에 $-200 \sim+170 \mathrm{MPa}$ 에서 $\mathrm{TGO}$ 가 성장함에 따라 초기의 마지막 사이클인 $1 \mu \mathrm{m}$ 두께의 $\mathrm{Al}_{2} \mathrm{O}_{3}$ 에서는 -90 $\sim+70 \mathrm{MPa}$ 로 감소되었다. 또한 인장응력이 발생하는 영 역이 사이클이 진행됨에 따라 peak부에서 off-peak부로 이 동되며 bond coat에 가해지는 기계적인 하중이 증가되었 다. 이러한 현상의 원인은 탄성적으로 거동성이 거의 없 는 TGO 스케일에 의해 bond coat의 수축이 방해받기 때 문에 bond coat와 $\mathrm{TBC}$ 사이의 열팽창 계수 차에 의한 $\mathrm{TBC}$ 의 부하를 감소시킨다. 이와 함께 $900 \sim 1150^{\circ} \mathrm{C}$ 의 고 온에서 $\mathrm{TGO}$ 는 매우 소프트하게 되어 misfit strain의 일부 분이 $\mathrm{TGO}$ 의 creep에 의해 완화된다.

\section{4. 결 론}

TBC-coated superalloy에 대한 $\mathrm{TGO}$ 의 swelling과 creep 효과를 고려하여 각 계면에서의 잔류응력 분포 변화를 유 한요소해석을 통하여 다음과 같은 결론을 얻을 수 있었다.
1. $\mathrm{TBC}$ 에서 swelling에 의해 발생된 응력의 크기는 $\mathrm{TBC}$ 와 $\mathrm{TGO}$ 의 creep relaxation에 의한 응력 완화 속도에 비 해 swelling에 의한 응력부가 변화에 크게 의존하는 것으 로 나타났다. TGO 스케일의 크리프 변형은 swelling에 의 한 $\mathrm{TBC}$ 의 응력을 완화시켜 결국 수명을 증가시켜 준다.

2. $\mathrm{TGO}$ 를 순수한 $\alpha-\mathrm{Al}_{2} \mathrm{O}_{3}$ 로 가정하여 크리프에 대한 문헌 자료를 바탕으로 $\mathrm{TGO}$ 의 입자 크기가 $1 \mu \mathrm{m}$ 이하로 작아진다면 본 모델링의 조건하에서는 swelling에 의한 응. 력을 효과적으로 감소시킬 수 있다는 것을 알 수 있었다.

\section{REFERENCES}

1. G. C. Chang and R. A. Miller, "Behavior of Thermal Barrier Coatings for Advanced Gas Turbine Blades," Surface and Coating Technology, 30 [1] 13-28 (1987).

2. A. G. Evans, D. R. Mumm, J. W. Hutchinson G. H. Meier, and F. S. Pettit, "Mechanisms Controlling the Durability of Thermal Barrier Coatings," Progress in Mater. Sci., 46 505. 53 (2001).

3. J. Muller and D. Neuschutz, "Efficiency of $\alpha$-Alumina as Diffusion Barrier between Bond Coat and Bulk Material of Gas Turbine Blades," Vacuum, 71 247-51 (2003).

4. W. J. Brindley and R. A. Miller, "Thermal Barrier Coating Life and Isothermal Oxidation of Low-Pressure PlasmaSprayed Bond Coat Alloys," Surface and Coating Technology, 43 [1-3] 446-57 (1990).

5. S. Sivakumar and B. L. Mordike, "High Temperature Coatings for Gas Turbine Blades: A Reviews," Surface and Coating Technology, 37 139-60 (1989).

6. P. W. Schilke, "Advanced Gas Turbine Materials and Coatings," GER-3569G, GE Energy Technical Document.

7. K. Kokini, Y. R. Takeuchi, and B. D. Chulus, "Surface Thermal Cracking Owing to Stress Relaxation; Zirconia vs. Mullite," Surface and Coating Technology, 82 77-82 (1996).

8. B. D. Choulus, K. Kokini, and T. A. Taylor, "Thermal Fracture of Ceramic Thermal Barrier Coatings under High Heat Flux with Time-Dependent Behavior-Part I: Experiment Results," Mater. Sci. Eng., A299 296-304 (2001).

9. R. C. Hendricks and G. McDonald, "The Effect of Annealing on the Creep of Plasma Sprayed Ceramics," pp. 13-6, Presented in Seventh Annual Conference on Ceramics and Advances Materials, Cocoa Beach, Florida, Jan., 1983.

10. T. Xu, M. Y. He, and A. G. Evans, "A Numerical Assessment of the Durability of Thermal Barrier Systems that Fail by Ratcheting of the Thermally Grown Oxide," Acta Mater., $513807-20$ (2003).

11. J. Schwarzer, D. Löhe, and O. Vöhringer, "Influence of the TGO Creep Behavior on Delamination Stress Development in Thermal Barrier Coating Systems," Mater. Sci. Eng. A, 387-389 692-95 (2004).

12. M. Martena, D. Botto, P. Fino, S. Sabbadini, M. M. Gola, and C. Badini, "Modelling of TBC System Failure: Stress Distribution as a Function of TGO Thickness and Thermal Expansion Mismatch," Engineering Failure Analysis, 13 [3] 
409-26 (2006).

13. J. C. Jang and S. C. Choi, "Numerical Simulation of Effects of TGO Growth and Asperity Ratio on Residual Stress Distributions in TC-BC-TGO Interface Region for Thermal Barrier Coatings(in Korean)," J. Kor. Ceram. Soc., 43 [7] 415-50 (2006).

14. J. T. DeMasi-Marcin, K. D. Sheffler, and S. Bose, "Mechanisms of Degradation and Failure in a Plasma Deposited Thermal Barrier Coating," J. Eng. Gas Turb. Power, 112
521-29 (1989)

15. A. M. Freborg, B. L. Ferguson, W. J. Brindley, and G. J. Petrus, "Modeling Oxidation Induced Stresses in Thermal Barrier Coatings," Mater. Sci. Eng. A, 245 [1] 182-90 (1998).

16. Y. C. Zhou and T. Hashida, "Coupled Effects of Temperature Gradient and Oxidation on Thermal Stress in Thermal Barrier Coating System," International Journal of Solid and Structures, 38 4235-64 (2001). 